See Article page e485.

\section{Commentary: Nitric oxide: An important contributor to neuroprotection during pediatric cardiac surgery}

\author{
Nobuyuki Ishibashi, MD, and Richard A. Jonas, MD
}

Microglia are the resident immune cells of the brain. They play a central role in neural immune function in reacting to a wide variety of brain insults. In addition, recent findings in developmental neuroscience highlight the importance of microglia for maturation and normal function of the central nervous system. ${ }^{1}$ We have previously shown that cardiopulmonary bypass $(\mathrm{CPB})$ and hypothermic circulatory arrest cause prolonged microglia expansion. ${ }^{2}$ The article by Kajimoto and colleagues ${ }^{3}$ from Seattle Children's Hospital in this issue of the Journal describes an interesting laboratory study using a translational piglet model. Study animals were ventilated with 20 parts per million of nitric oxide during reperfusion for approximately 3 hours before sacrifice. Subsequent morphologic analysis suggests that inhaled nitric oxide reduced microglial activation after $\mathrm{CPB}$ in the hippocampus.

Nitric oxide use during infant and pediatric CPB has become increasingly popular clinically following publication of a large prospective randomized clinical trial. ${ }^{4}$ The beneficial effects of nitric oxide were particularly apparent in patients younger than 6 weeks of age, who had significantly reduced length of intensive care unit stay and low cardiac output syndrome. In another clinical study, ${ }^{5}$ there was improved myocardial protection, improved fluid balance, and improved postoperative intensive care unit course consistent with a general anti-inflammatory effect of nitric

\footnotetext{
From the Division of Cardiovascular Surgery, Center for Neuroscience Research, and Sheikh Zayed Institute for Pediatric Surgical Innovation, Children's National Hospital, Washington, DC.

Disclosures: Authors have nothing to disclose with regard to commercial support.

Received for publication Dec 17, 2019; revisions received Dec 17, 2019; accepted for publication Dec 17, 2019; available ahead of print Jan 7, 2020.

Address for reprints: Richard A. Jonas, MD, Division of Cardiovascular Surgery, Children's National Hospital, 111 Michigan Ave NW, Washington, DC, 20010 (E-mail: rjonas@childrensnational.org or david.bichell@vumc.org); or Nobuyuki Ishibashi, MD, Center for Neuroscience Research and Sheikh Zayed Institute for Pediatric Surgical Innovation, Children's National Hospital, 111 Michigan Ave, NW, Washington, DC, 20010 (E-mail: nishibas@ childrensnational.org).

J Thorac Cardiovasc Surg 2021;161:e499-500

$0022-5223 / \$ 36.00$

Copyright (C) 2020 by The American Association for Thoracic Surgery

https://doi.org/10.1016/j.jtcvs.2019.12.057
}

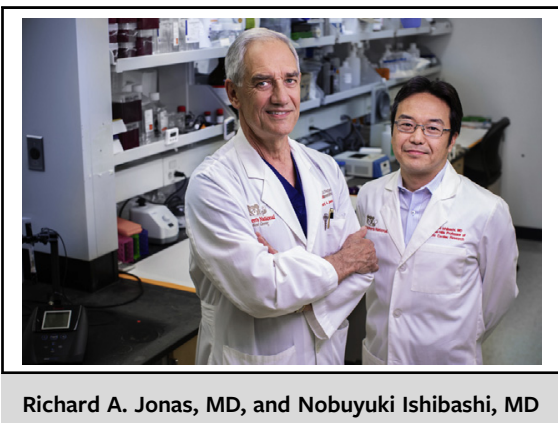

\author{
CENTRAL MESSAGE \\ Animal studies are elucidating \\ cellular mechanisms causing \\ disturbed brain development in \\ children with congenital heart \\ disease, leading to new therapies, \\ including application of nitric \\ oxide.
}

oxide that mitigates the systemic inflammatory response to CPB. We have also demonstrated a neuroprotective effect of nitric oxide during CPB and deep hypothermic circulatory arrest using magnetic resonance spectroscopy. ${ }^{6}$ The present report further supports the notion that nitric oxide can be an important contributor to protect neurons and glial cells from insults associated with CPB and deep hypothermic circulatory arrest.

It is now clear that the etiology of neurologic deficits in children with congenital heart disease (CHD) is cumulative and multifactorial. ${ }^{7}$ Alterations in fetal cerebral oxygen delivery cause immature and delayed brain development before birth and before surgery. Lawrence and colleagues ${ }^{8}$ recently demonstrated with a unique "artificial womb" system that prenatal and preoperative chronic hypoxemia result in similar alterations in microglial morphology in fetal sheep. Several clinical studies demonstrate that further brain damage commonly occurs postoperatively in the individual who has brain immaturity due to fetal hypoxia. Therefore, future studies will be required to determine the effects of cardiac surgery on the brain that contains microglia that are already activated and toxic to develop the optimal regimen of nitric oxide for neuroprotection.

Many children with complex CHD suffer important developmental delay and neurobehavioral problems. Despite the limitations as described by the authors, we congratulate them for performing a series of challenging 
animal studies and exploring possible pharmacologic therapy for children with CHD. Going forward, further integration with neuroscience research will be helpful in designing experiments to determine the complex cellular events underlying brain injury. Hopefully, the knowledge gained will lead to treatment to protect immature brains during pediatric cardiac surgery. As the present report and recent studies indicate, ${ }^{8,9}$ animal studies show great promise in elucidating the cellular etiologies of disturbed brain development in the CHD population and establishing new approaches for improvement of neurologic development.

\section{References}

1. Wake H, Moorhouse AJ, Miyamoto A, Nabekura J. Microglia: actively surveying and shaping neuronal circuit structure and function. Trends Neurosci. 2013;36: 209-17.

2. Korotcova L, Kumar S, Agematsu K, Morton PD, Jonas RA, Ishibashi N. Prolonged white matter inflammation after cardiopulmonary bypass and circulatory arrest in a juvenile porcine model. Ann Thorac Surg. 2015;100:1030-7.
3. Kajimoto M, Nuri M, Sleasman JR, Charette K, Nelson BR, Portman MA. Inhaled nitric oxide reduces injury and microglia activation in porcine hippocampus after deep hypothermic circulatory arrest. J Thorac Cardiovasc Surg. 2021;161: e485-98.

4. James C, Millar J, Horton S, Brizard C, Molesworth C, Butt W. Nitric oxide administration during paediatric cardiopulmonary bypass: a randomised controlled trial. Intensive Care Med. 2016;42:1744-52.

5. Checchia PA, Bronicki RA, Muenzer JT, Dixon D, Raithel S, Gandhi SK, et al. Nitric oxide delivery during cardiopulmonary bypass reduces postoperative morbidity in children - a randomized trial. J Thorac Cardiovasc Surg. 2013; 146:530-6.

6. Hiramatsu T, Jonas RA, Miura T, duPlessis A, Tanji M, Forbess JM, et al. Cerebral metabolic recovery from deep hypothermic circulatory arrest after treatment with arginine and nitro-arginine methyl ester. J Thorac Cardiovasc Surg. 1996;112: 698-707.

7. Morton PD, Ishibashi N, Jonas RA. Neurodevelopmental abnormalities and congenital heart disease: insights into altered brain maturation. Circ Res. 2017; 120:960-77.

8. Lawrence KM, McGovern PE, Mejaddam A, Rossidis AC, Baumgarten H, Kim AG, et al. Prenatal hypoxemia alters microglial morphology in fetal sheep. J Thorac Cardiovasc Surg. January 6, 2020 [Epub ahead of print].

9. Leonetti C, Back SA, Gallo V, Ishibashi N. Cortical dysmaturation in congenital heart disease. Trends Neurosci. 2019;42:192-204.
See Article page e485.

\section{Commentary: A miracle product, applied early and often}

\author{
David Bichell, MD
}

Publications about nitric oxide (NO) topped 6000 per year through the early 2000s, describing actions in cardiovascular biology, cancer, immunology, and neurology. NO-mediated endothelial dysfunction underlies a broad array of diseases, and NO is a putative miracle product to the rescue. ${ }^{1}$ As some applications of NO in congenital heart surgery are maturing toward standard-of-care status, new clinical applications are emerging, some effective and some remaining good news only for piglets and rats.

\footnotetext{
From the Department of Cardiac Surgery, Monroe Carell, Jr, Children's Hospital, Vanderbilt University Medical Center, Nashville, Tenn.

Disclosures: Author has nothing to disclose with regard to commercial support.

Received for publication Dec 21, 2019; accepted for publication Dec 23, 2019; available ahead of print Jan 11, 2020.

Address for reprints: David P. Bichell, MD, Department of Cardiac Surgery, Monroe Carell, Jr, Children's Hospital, Vanderbilt University Medical Center, 5247 Doctors' Office Tower, 2200 Children's Way, Nashville, TN 37232-9292 (E-mail: david.bichell@vumc.org).

J Thorac Cardiovasc Surg 2021;161:e500-1 $0022-5223 / \$ 36.00$

Copyright $₫ 2020$ Published by Elsevier Inc. on behalf of The American Association for Thoracic Surgery

https://doi.org/10.1016/j.jtcvs.2019.12.084
}

Check for updates

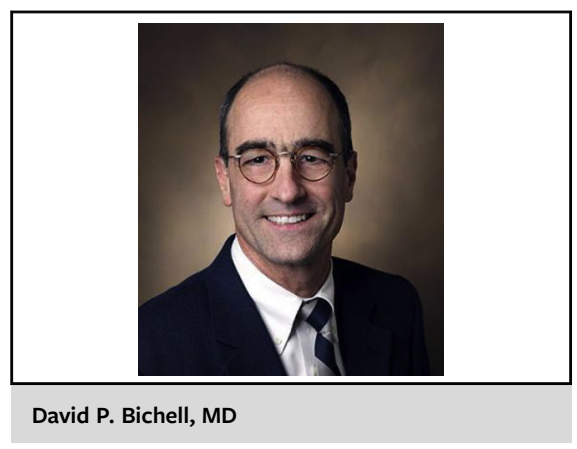

CENTRAL MESSAGE

Mitigating microglia-mediated

brain damage may be among

reasons for administering nitric

oxide at reperfusion from car-

diopulmonary bypass, but clinical

relevance remains unproven.

Checchia and colleagues ${ }^{2}$ showed a reduction in serum inflammatory markers and myocardial injury and shorter mechanical ventilation and intensive care unit stay in pediatric patients undergoing tetralogy of Fallot repair who had NO delivered to the $\mathrm{CPB}$ circuit. A randomized prospective trial of children undergoing cardiopulmonary bypass (CPB) at 